\title{
Coverage and equity in reproductive and maternal health interventions in Brazil: impressive progress following the implementation of the Unified Health System
}

Giovanny V. A. França ${ }^{\dagger}$, María Clara Restrepo-Méndez ${ }^{\dagger}$, Maria Fátima S. Maia, Cesar G. Victora and Aluísio J. D. Barros ${ }^{*}$

\begin{abstract}
Background: The Brazilian SUS (Unified Health System) was created in 1988 within the new constitution, based on the premises of being universal, comprehensive, and equitable. The SUS offers free health care, independent of contribution or affiliation. Since then, great efforts and increasing investments have been made for the system to achieve its goals. We assessed how coverage and equity in selected reproductive and maternal interventions progressed in Brazil from 1986 to 2013.

Methods: We reanalysed data from four national health surveys carried out in Brazil in 1986, 1996, 2006 and 2013. We estimated coverage for six interventions [use of modern contraceptives; antenatal care (ANC) 1+ visits by any provider; ANC 4+ visits by any provider; first ANC visit during the first trimester of pregnancy; institutional delivery; and Caesarean sections] using standard international definitions, and stratified results by wealth quintile, urban or rural residence and country regions. We also calculated two inequality indicators: the slope index of inequality (SII) and the concentration index (CIX).

Results: All indicators showed steady increases in coverage over time. ANC $1+$ and $4+$ and institutional delivery reached coverage above $90 \%$ in 2013. Prevalence of use of modern contraceptives was $83 \%$ in 2013, indicating nearly universal satisfaction of need for contraception. On a less positive note, the proportion of C-sections has also grown continuously, reaching $55 \%$ in 2013. There were marked reductions in wealth inequalities for all preventive interventions. Inequalities were significantly reduced for all indicators except for the C-section rate $(p=0.06)$, particularly in absolute terms (SII).

Conclusions: Despite the difficulties faced in the implementation of SUS, coverage of essential interventions increased and equity has improved dramatically, due in most cases to marked increase in coverage among the poorest $40 \%$. An increase in unnecessary Caesarean sections was also observed during the period. Further evaluation on the quality of healthcare provided is needed.
\end{abstract}

Keywords: Maternal health, Health inequalities, Socioeconomic factors, Brazil

\footnotetext{
* Correspondence: abarros@equidade.org

${ }^{\dagger}$ Equal contributors

International Center for Equity in Health, Federal University of Pelotas, Rua

Marechal Deodoro, $11603^{\circ}$ Piso, 96020-220 Pelotas, RS, Brazil
} 


\section{Background}

Social inequalities are still a major problem in Latin America in spite of recent economic growth $[1,2]$. Health inequalities are also a leading health problem in the region [1-3]. In response to these challenges, substantial increases in public funding for social programmes and the adoption of relevant policies and strategic health-related initiatives took place in the region over the past few decades [3, 4]. Brazil provides an example of a distinct approach to health-system reform, combining poverty reduction strategies with the expansion of comprehensive primary health care services [5, 6]. Hence, lessons from the Brazilian experience are relevant for countries advancing in universal health coverage.

The health sector reform in Brazil is unique because it was driven by civil society rather than by governments, political parties, or international organizations [5, 7]. It was designed by militants of the so-called Sanitary Movement nearly a decade before health care was incorporated in the 1998 Constitution as a citizen's right and State's duty [7-9]. In the 1990's health sector reform was institutionalised with the creation of a national Unified Health System (SUS, Sistema Único de Saúde), based on the principles of universality, equity, integrality and social participation $[5,8]$.

Since then, the SUS became a driving force for equalizing access to services by offering free and comprehensive health care for all, independent of contribution or affiliation [5, 9]. Other advances during the past 20 years included investments in human resources, primary care, science and technology, decentralization, widespread social participation, and growing public awareness of a right to health care. Among the many programs and policies put in place since the inception of SUS, two are of major importance. First, the Family Health Program changed the structure of traditional primary health care centres, adding community health workers and defining catchment areas for facilities. The program was targeted at the poorest, under-served urban neighbourhoods and rural areas [10]. Later, the Programa Bolsa Família, a conditional cash transfer program, unified several social benefit initiatives in one large program designed to provide extra cash to the poorest families in the country, conditional on use of health services by children and on regular school attendance. The program was successful in reducing income inequality [11], contributing to a significant decrease in childhood mortality, especially from poverty-related causes such as malnutrition and diarrhea [12]. In parallel, the country went through a period of rapid economic changes, with the control of hyperinflation in 1994, and strong economic growth between 2004 and 2011.
Despite criticisms regarding underfunding and poor management of the SUS, as well as of the unequal distribution of power and resources, [8] there is mounting evidence that health inequalities in Brazil have been steadily declining [5]. Since 1990's, Brazil has increased intervention coverage in maternal and child interventions, reduced inequalities in terms of under-5 mortality and practically eliminated inequalities in stunting [2]. However, it is worth noting that most of this evidence is based on the Brazilian household survey conducted in 2006, and therefore, no reliable population-based data on maternal and child health has been available for the last 9 years. In this article, we describe how coverage and inequalities in reproductive and maternal health interventions evolved over time, based on the analyses of four national household surveys carried out from 1986 to 2013 , covering a period of nearly three decades.

\section{Methods \\ Study design and data sources}

The International Centre for Equity in Health (ICEH, www.equidade.org) monitors equity in health and nutrition by reanalysing population-based surveys, especially the Demographic and Health Surveys (DHS) and Multiple Indicator Cluster Surveys (MICS). Our analyses relied on data from the following national surveys carried out in Brazil: Demographic Health Surveys - 1986 [13] and 1996 [14]; Pesquisa Nacional de Demografia e Saúde (PNDS), a survey similar to DHS carried out in 2006, funded by the Ministry of Health [15]; and the National Health Survey (PNS) carried out in 2013 by the Brazilian Statistics Office (IBGE) and the Oswaldo Cruz Foundation [16].

\section{Selection of indicators}

Out of a set of 80 reproductive, maternal, newborn and child health $(\mathrm{RMNCH})$ indicators routinely calculated by the ICEH, data were available for six reproductive and maternal interventions for at least three out of the four surveys under study. We applied the following definitions:

- Use of modern contraceptives: percentage of women age 15-49 years currently married or in union who are using (or whose partner is using) a modern contraceptive method;

- Antenatal care $1+$ visits (ANC 1+): percentage of women aged 15-49 with a live birth in the survey reference period who had one or more ANC-related visits during pregnancy, by any provider;

- Antenatal care 4+ visits (ANC 4+): percentage of women aged 15-49 with a live birth in the survey reference period who had four or more ANC-related visits during pregnancy, by any provider; 
- First ANC visit during the first trimester of pregnancy: percentage of women aged 15-49 with a live birth in the survey reference period who underwent the first prenatal visit during the first trimester of pregnancy;

- Institutional delivery: percentage of live births which took place in a health facility;

- C-sections rate: percentage of live births delivered by Caesarean section.

Survey reference periods included births in the past 5 years in the first three surveys, and in the past 2 years for the 2013 survey.

\section{Data analyses}

All analyses were carried out in Stata (StataCorp. 2013. Stata Statistical Software: Release 13. College Station, TX: StataCorp LP), taking into account the survey design, including sampling weights and clustering. All point estimates of coverage and inequality indices were calculated with standard errors, based on the original data sets. Indicators were disaggregated by household wealth quintiles based on asset indices, urban and rural residence and country region. Asset indices [17] were calculated by the DHS team for the 1996 survey; for the other three surveys, we used similar methods to derive asset indices using principal component analyses based on household goods, characteristics of the house and available infrastructure, such as types of water access and sanitation facilities. Asset indices were grouped into quintiles, with Q1 representing the poorest and Q5 the wealthiest $20 \%$ of households.

\section{Measures of inequalities}

We calculated two inequality indicators that take the whole distribution of wealth into account: the slope index of inequality (SII) and the concentration index (CIX). The SII expresses the absolute difference in percentage points between the projected coverage for the top and the bottom of the wealth distribution, [18] using a logistic regression model. The CIX is based on concept similar to the Gini index for income concentration,

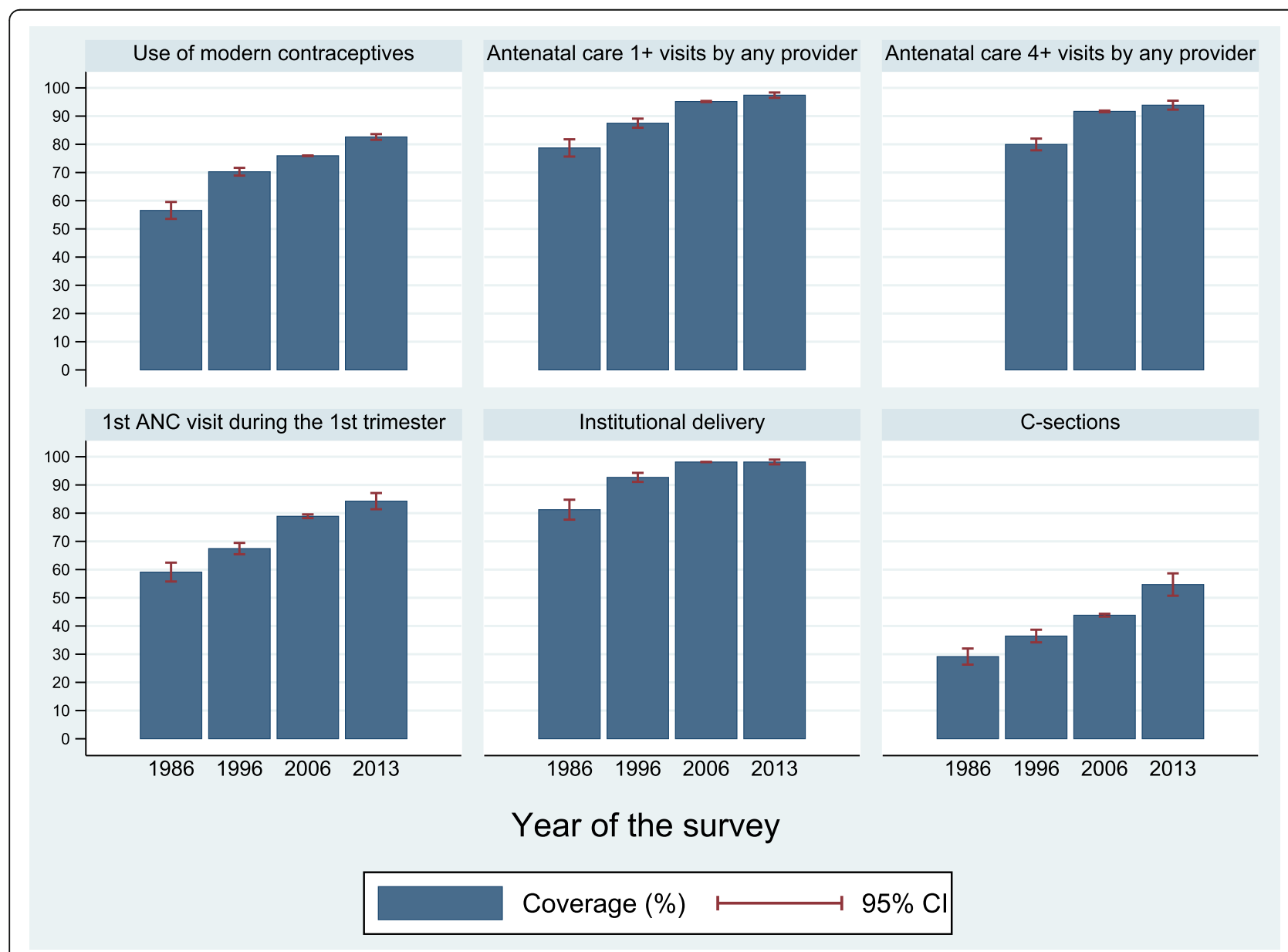

Fig. 1 National coverage of six reproductive and maternal interventions, Brazil, from 1986 to 2013. Source: Brazil DHS 1986, DHS 1996, PNDS 2006, PNS 2013 
being expressed on a scale from -100 to +100 , with zero representing equal distribution of the attribute across the wealth scale. Positive CIX values represent a pro-rich distribution, usually observed for health coverage indicators. The SII expresses absolute inequality, whereas the CIX expresses relative inequality $[18,19]$.

\section{Time trends}

Variance-weighted least squares regression was used to estimate the average absolute annual change in coverage and in inequality measures taking into account the time intervals between surveys, allowing tests of the statistical significance of the observed trends. Survey year was used as the independent variable in the time trend analyses. Annual changes were estimated at the national level, for the poorest (Q1) and richest (Q5) quintiles, and for CIX and SII. Absolute changes are expressed in percentage points per year. Results were omitted when the unweighted number of observations in a specific subgroup was less than 25 .
Ethics

We used publicly available data from national surveys in our analyses. Ethical clearance was obtained by the institutions that carried out the surveys. Further information about the surveys and ethics can be found in their respective websites [20-23]. The PNS project was approved by the National Commission of Ethics in Research (CONEP) in June 2013, Regulation No. 328.159.

\section{Results}

We were able to calculate the selected indicators for all surveys, except for ANC 4+ visits in the 1986 survey in which the number of visits was not recorded. Figure 1 shows the national coverage of the six interventions (Table 1). All indicators showed steady increase in coverage over the years. ANC $1+$ and $4+$ and institutional delivery reached coverage above $90 \%$ in 2013. Prevalence of use of modern contraceptives was $83 \%$ in 2013, what corresponds to $95 \%$ of

Table 1 Coverage of six reproductive and maternal interventions by geographic region, Brazil, from 1986 to 2013

\begin{tabular}{|c|c|c|c|c|c|c|c|c|c|c|}
\hline \multirow{4}{*}{$\begin{array}{l}\text { Indicator } \\
\text { Use of modern contraceptives }\end{array}$} & \multirow{4}{*}{\begin{tabular}{|l|} 
Year \\
1986 \\
\end{tabular}} & \multirow{2}{*}{\multicolumn{3}{|c|}{ National }} & \multicolumn{6}{|c|}{ Area of residence } \\
\hline & & & & & \multicolumn{3}{|c|}{ Urban } & \multicolumn{3}{|c|}{ Rural } \\
\hline & & & \multicolumn{2}{|c|}{$95 \% \mathrm{Cl}$} & \multirow{2}{*}{$\begin{array}{l}\% \\
63.6\end{array}$} & \multicolumn{2}{|c|}{$95 \% \mathrm{Cl}$} & \multirow{2}{*}{$\begin{array}{l}\% \\
43.3\end{array}$} & \multicolumn{2}{|c|}{$95 \% \mathrm{Cl}$} \\
\hline & & & 53.6 & 59.6 & & 60.9 & 66.3 & & 37.1 & 49.4 \\
\hline & 1996 & 70.3 & 68.9 & 71.7 & 72.6 & 71.2 & 74.1 & 61.2 & 57.8 & 64.6 \\
\hline & 2006 & 75.9 & 75.8 & 76.0 & 76.0 & 75.9 & 76.2 & 75.5 & 75.1 & 75.9 \\
\hline & 2013 & 82.6 & 81.6 & 83.6 & 83.0 & 81.9 & 84.0 & 80.3 & 77.6 & 82.9 \\
\hline \multirow[t]{4}{*}{ Antenatal care $1+$ visits (any provider) } & 1986 & 78.7 & 75.7 & 81.8 & 88.2 & 85.5 & 91.0 & 56.8 & 50.9 & 62.7 \\
\hline & 1996 & 87.5 & 85.9 & 89.1 & 92.0 & 90.7 & 93.2 & 72.0 & 66.9 & 77.0 \\
\hline & 2006 & 95.2 & 95.0 & 95.4 & 96.4 & 96.3 & 96.6 & 89.5 & 86.4 & 92.6 \\
\hline & 2013 & 97.4 & 96.5 & 98.4 & 97.4 & 96.3 & 98.5 & 97.5 & 95.7 & 99.3 \\
\hline \multirow[t]{4}{*}{ Antenatal care $4+$ visits (any provider) } & 1986 & NA & NA & NA & NA & NA & NA & NA & NA & NA \\
\hline & 1996 & 79.9 & 77.9 & 82.0 & 86.0 & 84.2 & 87.8 & 59.1 & 53.2 & 65.1 \\
\hline & 2006 & 91.7 & 91.4 & 92.0 & 93.5 & 93.3 & 93.7 & 83.4 & 80.1 & 86.8 \\
\hline & 2013 & 93.9 & 92.3 & 95.5 & 94.5 & 92.9 & 96.1 & 90.6 & 85.3 & 95.9 \\
\hline \multirow[t]{4}{*}{ 1st ANC visit during the 1st trimester } & 1986 & 59.1 & 55.8 & 62.5 & 69.2 & 65.7 & 72.8 & 35.9 & 31.0 & 40.7 \\
\hline & 1996 & 67.4 & 65.4 & 69.5 & 72.7 & 70.8 & 74.7 & 49.3 & 44.4 & 54.1 \\
\hline & 2006 & 78.9 & 78.2 & 79.6 & 79.6 & 78.7 & 80.4 & 75.8 & 74.1 & 77.5 \\
\hline & 2013 & 84.3 & 81.4 & 87.1 & 85.3 & 82.3 & 88.4 & 78.6 & 70.6 & 86.6 \\
\hline \multirow[t]{4}{*}{ Institutional delivery } & 1986 & 81.2 & 77.7 & 84.8 & 92.0 & 89.8 & 94.2 & 59.8 & 53.4 & 66.1 \\
\hline & 1996 & 92.7 & 91.1 & 94.3 & 96.9 & 96.0 & 97.8 & 79.6 & 74.4 & 84.7 \\
\hline & 2006 & 98.1 & 98.1 & 98.2 & 98.7 & 98.7 & 98.7 & 95.8 & 95.6 & 96.1 \\
\hline & 2013 & 98.1 & 97.3 & 99.0 & 99.2 & 98.7 & 99.8 & 92.4 & 88.1 & 96.7 \\
\hline \multirow[t]{4}{*}{ C-sections } & 1986 & 29.2 & 26.3 & 32.0 & 36.2 & 33.1 & 39.4 & 15.1 & 11.4 & 18.8 \\
\hline & 1996 & 36.4 & 34.2 & 38.7 & 41.8 & 39.2 & 44.3 & 20.1 & 16.3 & 23.9 \\
\hline & 2006 & 43.8 & 43.3 & 44.3 & 45.9 & 45.3 & 46.5 & 35.2 & 32.6 & 37.9 \\
\hline & 2013 & 54.7 & 50.7 & 58.7 & 58.2 & 53.8 & 62.6 & 36.0 & 28.0 & 44.0 \\
\hline
\end{tabular}


family planning coverage (percent of women in need that are using contraception) according to a recently published paper (REF). On a less positive note, the proportion of C-sections has also grown continuously, reaching $55 \%$ in 2013.

Coverage trends for geographic regions are presented in Fig. 2 (Table 2). The Northeast and North regions showed marked increases for most indicators over time. By 2013 these regions reached coverage levels similar to those in the wealthiest regions (Southeast and South), except for the C-section rate. The North region is slightly behind in terms of ANC visits in the first trimester.

Figure 3 (Table 1) shows coverage trends in urban and rural areas. Urban coverage was substantially larger in 1986. These differences were attenuated and virtually disappeared by 2013 for use of modern contraceptives, ANC 1+ and ANC 4+ visits. Regarding Csections, the increase between 2006 and 2013 was restricted to urban women, thus widening the urbanrural gap (58.3 \% vs. $36.0 \%)$.
Figure 4 present coverage by wealth over time. Each circle represents coverage in each wealth quintile. Horizontal lines connect the poorest and wealthiest quintiles, with longer lines representing larger absolute inequalities. There were large reductions in inequalities for all interventions. Use of contraceptives, ANC and institutional deliveries presented bottom inequality early on [19] with the poorest $20 \%$ being well behind the other groups. Disparities in C-section rates were those with the smallest reduction (Table 3).

Figure 5 shows scatter diagrams of changes in CIX and SII. According to absolute inequalities (SII), the first ANC visit during the first trimester of pregnancy was the most inequitable intervention in 1986, but substantial progress was achieved over time. In 2013, the most inequitable intervention was C-section, which showed little progress in terms of absolute inequalities. Substantial decreases in relative inequalities (CIX) were achieved for all indicators. Although the CIX for C-section was reduced by half from 1986 to 2013, it remained as the most inequitable intervention in relative terms (Table 3).

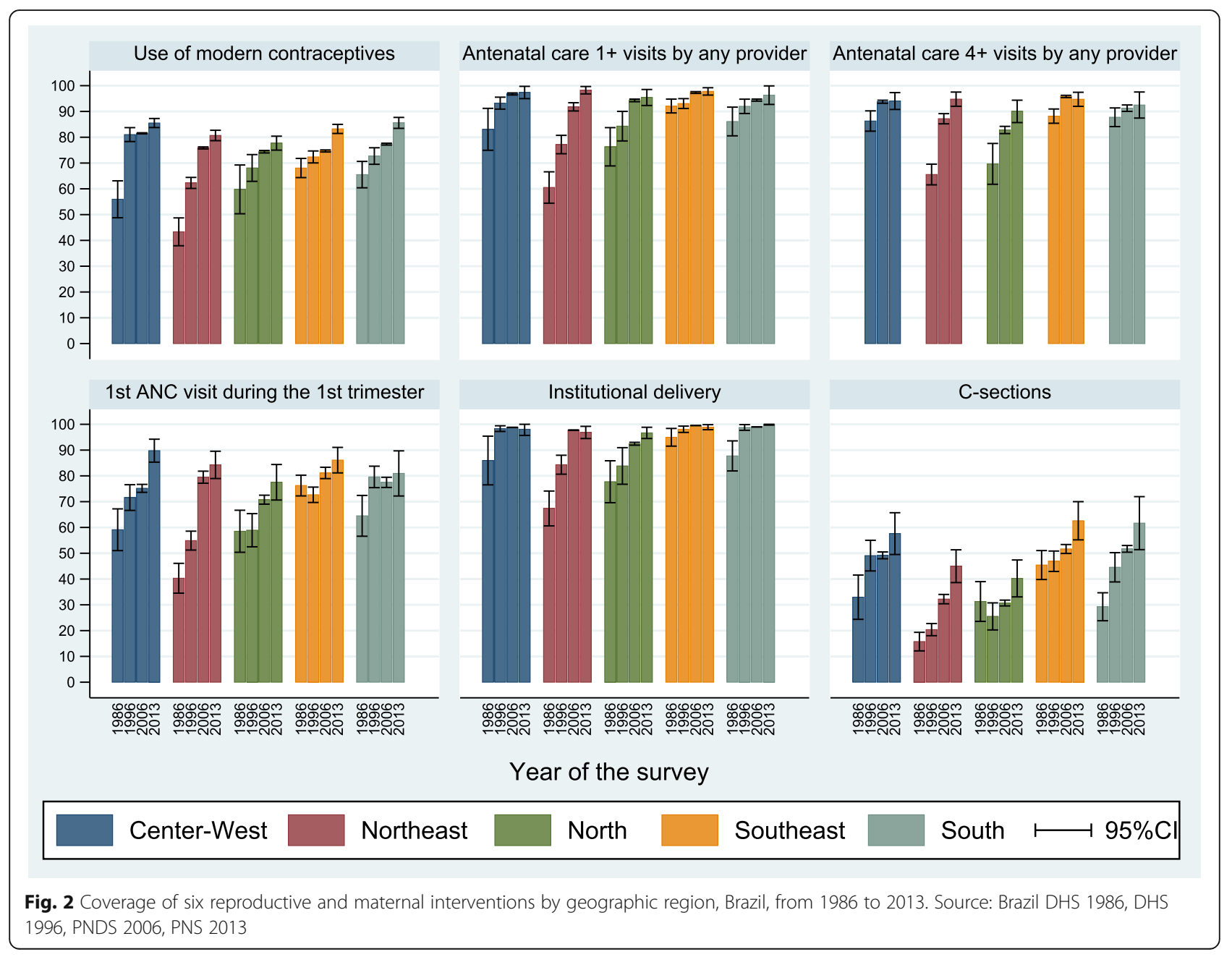


Table 2 Coverage of six reproductive and maternal interventions by geographic region, Brazil, from 1986 to 2013

\begin{tabular}{|c|c|c|c|c|c|c|c|c|c|c|c|c|c|c|c|c|}
\hline \multirow{4}{*}{$\begin{array}{l}\text { Indicator } \\
\text { Use of modern contraceptives }\end{array}$} & \multirow{4}{*}{$\begin{array}{l}\text { Year } \\
1986\end{array}$} & \multicolumn{15}{|c|}{ Region of the country } \\
\hline & & \multicolumn{3}{|c|}{ Center-West } & \multicolumn{3}{|c|}{ North } & \multicolumn{3}{|c|}{ Northeast } & \multicolumn{3}{|c|}{ Southeast } & \multicolumn{3}{|c|}{ South } \\
\hline & & \multirow{2}{*}{$\begin{array}{l}\% \\
55.9\end{array}$} & \multicolumn{2}{|c|}{$95 \% \mathrm{Cl}$} & \multirow{2}{*}{$\begin{array}{l}\% \\
59.8\end{array}$} & \multicolumn{2}{|c|}{$95 \% \mathrm{Cl}$} & \multirow{2}{*}{$\begin{array}{l}\% \\
43.3\end{array}$} & \multicolumn{2}{|c|}{$95 \% \mathrm{Cl}$} & \multirow{2}{*}{$\begin{array}{l}\% \\
68.1\end{array}$} & \multicolumn{2}{|c|}{$95 \% \mathrm{Cl}$} & \multirow{2}{*}{$\frac{\%}{65.5}$} & \multicolumn{2}{|c|}{$95 \% \mathrm{Cl}$} \\
\hline & & & 48.8 & 63.1 & & 50.3 & 69.2 & & 37.9 & 48.7 & & 64.3 & 71.8 & & 60.4 & 70.6 \\
\hline & 1996 & 81.0 & 78.3 & 83.7 & 68.1 & 62.9 & 73.3 & 62.3 & 60.2 & 64.4 & 72.4 & 70.0 & 74.7 & 72.7 & 69.5 & 75.9 \\
\hline & 2006 & 81.5 & 81.3 & 81.7 & 74.4 & 73.9 & 74.9 & 75.9 & 75.5 & 76.2 & 74.7 & 74.3 & 75.1 & 77.3 & 77.0 & 77.7 \\
\hline & 2013 & 85.5 & 83.8 & 87.3 & 77.7 & 75.0 & 80.4 & 80.7 & 78.7 & 82.7 & 83.2 & 81.5 & 85.0 & 85.6 & 83.4 & 87.7 \\
\hline \multirow[t]{4}{*}{ Antenatal care 1+ visits (any provider) } & 1986 & 83.1 & 74.9 & 91.2 & 76.3 & 68.9 & 83.7 & 60.5 & 54.4 & 66.6 & 92.1 & 89.4 & 94.8 & 86.1 & 80.5 & 91.7 \\
\hline & 1996 & 93.2 & 90.9 & 95.5 & 84.3 & 78.6 & 90.0 & 77.2 & 73.6 & 80.7 & 93.1 & 91.2 & 95.0 & 92.0 & 89.2 & 94.8 \\
\hline & 2006 & 96.8 & 96.4 & 97.2 & 94.3 & 93.8 & 94.8 & 91.8 & 90.2 & 93.4 & 97.3 & 97.0 & 97.7 & 94.4 & 94.0 & 94.8 \\
\hline & 2013 & 97.3 & 95.0 & 99.7 & 95.4 & 92.3 & 98.5 & 98.2 & 96.8 & 99.7 & 97.8 & 96.4 & 99.2 & 96.3 & 92.7 & 99.9 \\
\hline \multirow[t]{4}{*}{ Antenatal care $4+$ visits (any provider) } & 1986 & NA & NA & NA & NA & NA & NA & NA & NA & NA & NA & NA & NA & NA & NA & NA \\
\hline & 1996 & 86.3 & 82.3 & 90.2 & 69.7 & 61.8 & 77.6 & 65.5 & 61.5 & 69.6 & 88.2 & 85.4 & 91.0 & 87.8 & 84.1 & 91.4 \\
\hline & 2006 & 93.8 & 93.2 & 94.4 & 82.8 & 81.4 & 84.2 & 87.2 & 85.2 & 89.1 & 95.8 & 95.4 & 96.3 & 91.3 & 90.0 & 92.5 \\
\hline & 2013 & 94.0 & 90.8 & 97.3 & 90.0 & 85.7 & 94.4 & 94.8 & 92.0 & 97.5 & 94.7 & 92.0 & 97.4 & 92.5 & 87.4 & 97.5 \\
\hline \multirow[t]{4}{*}{ 1st ANC visit during the 1st trimester } & 1986 & 59.1 & 51.0 & 67.2 & 58.5 & 50.4 & 66.7 & 40.3 & 34.5 & 46.1 & 76.3 & 72.2 & 80.3 & 64.5 & 56.6 & 72.4 \\
\hline & 1996 & 71.6 & 66.6 & 76.6 & 58.9 & 52.5 & 65.4 & 54.9 & 51.2 & 58.6 & 72.7 & 69.7 & 75.6 & 79.6 & 75.4 & 83.8 \\
\hline & 2006 & 75.2 & 73.6 & 76.7 & 70.8 & 69.0 & 72.5 & 79.5 & 77.2 & 81.8 & 81.1 & 78.9 & 83.3 & 77.5 & 75.5 & 79.5 \\
\hline & 2013 & 89.8 & 85.3 & 94.2 & 77.5 & 70.6 & 84.4 & 84.3 & 79.0 & 89.5 & 86.1 & 81.2 & 91.0 & 80.9 & 72.2 & 89.7 \\
\hline \multirow[t]{4}{*}{ Institutional delivery } & 1986 & 86.0 & 76.5 & 95.4 & 77.7 & 69.6 & 85.9 & 67.4 & 60.6 & 74.1 & 95.0 & 91.5 & 98.4 & 87.7 & 81.9 & 93.6 \\
\hline & 1996 & 98.3 & 97.2 & 99.4 & 83.8 & 76.7 & 90.9 & 84.3 & 80.7 & 88.0 & 98.1 & 96.8 & 99.3 & 98.8 & 97.7 & 99.9 \\
\hline & 2006 & 98.8 & 98.8 & 98.8 & 92.5 & 91.9 & 93.0 & 97.7 & 97.6 & 97.8 & 99.5 & 99.5 & 99.5 & 99.0 & 98.9 & 99.0 \\
\hline & 2013 & 98.1 & 95.7 & 100.0 & 96.7 & 94.5 & 98.8 & 96.8 & 94.5 & 99.2 & 98.9 & 97.9 & 99.8 & 99.9 & 99.7 & 100.0 \\
\hline \multirow[t]{4}{*}{ C-sections } & 1986 & 33.0 & 24.4 & 41.5 & 31.3 & 23.6 & 39.0 & 15.7 & 12.1 & 19.3 & 45.4 & 39.8 & 51.0 & 29.2 & 23.8 & 34.7 \\
\hline & 1996 & 49.1 & 43.1 & 55.0 & 25.5 & 20.3 & 30.8 & 20.4 & 18.0 & 22.7 & 46.9 & 42.9 & 50.9 & 44.6 & 38.9 & 50.2 \\
\hline & 2006 & 49.2 & 47.9 & 50.5 & 30.7 & 29.6 & 31.8 & 32.2 & 30.4 & 34.0 & 51.7 & 49.9 & 53.4 & 51.7 & 50.4 & 53.0 \\
\hline & 2013 & 57.6 & 49.5 & 65.7 & 40.2 & 33.1 & 47.4 & 45.0 & 38.6 & 51.3 & 62.6 & 55.2 & 70.0 & 61.7 & 51.4 & 71.9 \\
\hline
\end{tabular}

Source: Brazil DHS 1986, DHS 1996, PNDS 2006, PNS 2013. NA not available, 95 \% Cl 95 \% confidence interval

Significant increases in overall coverage were found for all indicators, as well as for the poorest and wealthiest $20 \%$ for most indicators (Table 4). In contrast, the antenatal and delivery care indicators did not increase over time among the $20 \%$ wealthiest women. Absolute and relative equity improved significantly for nearly all indicators with greater reductions in terms of absolute than of relative inequality, except for $\mathrm{C}$-sections rate $(p=0.06)$.

\section{Discussion}

In spite of its economic growth up to the recent past, Brazil is still among the five Latin American countries with the greatest income inequalities $[24,25]$. Nevertheless, our findings show improved equity in access to health services as can be seen by increased coverage in reproductive and maternal health interventions and the remarkable reductions in geographic and wealth-related inequalities. Even the poorest $20 \%$ of women and those living in rural or remote areas achieved near universal coverage levels with preventive interventions by 2013. To date, this is the first study to examine the evolution of coverage and inequalities of a relevant set of maternal health interventions covering a period of three decades and including the most recent data from national household surveys in Brazil. In addition, this article presents the most complete evidence of universal coverage achievement in terms of maternal health interventions.

In terms of improving equity, the best possible combination is when both absolute and relative indices improve; this was the case Brazil for all selected interventions, that shows important progress across all quintiles of wealth index and also faster progress among the poorest $20 \%$.

Several factors seem to have contributed to increasing coverage and reducing inequalities, [6], including economic growth, reduction in income inequality, urbanisation, improved education, and decreased fertility. The control of hyperinflation in 1994, modernization of the Brazilian economy, high Gross Domestic Product (GDP) 


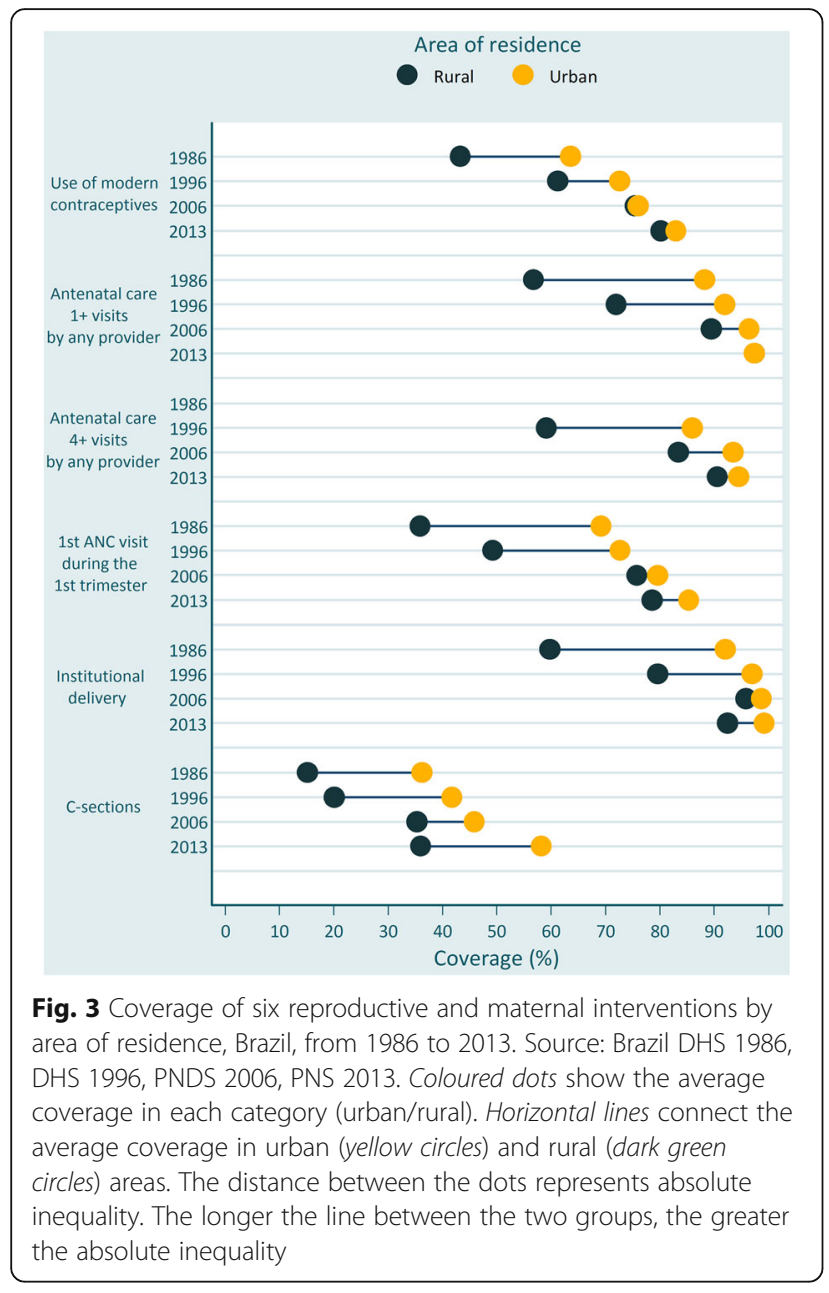

growth rates between 2004 and 2011, and increased social investment contributed to this positive scenario. Anti-poverty actions such as the conditional cash transfer programme (Programa Bolsa Família) are likely to have contributed to the changes.

Within the health sector, the creation of the taxfunded national health system (SUS) in 1988 extended free health care to a significant proportion of the population that was excluded until then, mostly rural workers and the unemployed or informal workers [5, 9]. Before the inception of SUS, Brazil's healthcare system was based on private organizations that received large government subsidies. An important program was the Family Health Program (Programa Saúde da Família - PSF), established in the mid-1990s, which expanded the primary health care network to reach the poorest areas of the country. Its innovative approach of starting with areas that were devoid of any services, and the inclusion of community health workers to the health team was enormously successful, with its coverage expanding rapidly since its inception, reaching $55 \%$ in 2012 [3, 4, 6, 9]. The SUS also includes a National Immunisation Programme (PNI) and

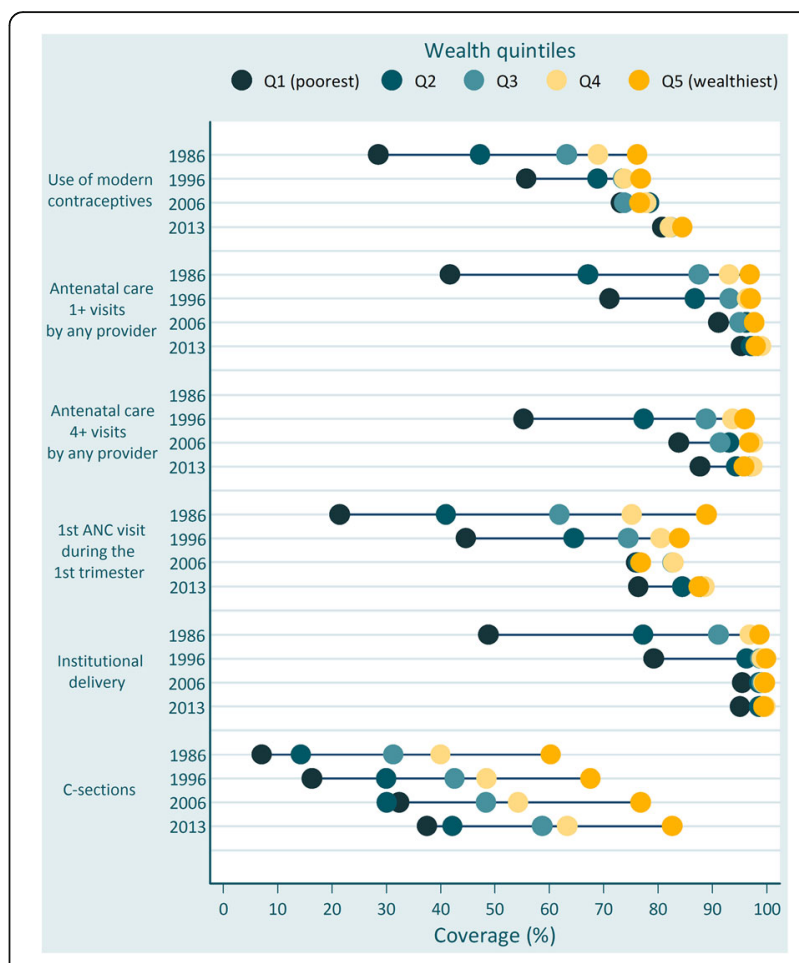

Fig. 4 Coverage of six reproductive and maternal interventions by wealth quintiles, Brazil, from 1986 to 2013. Source: Brazil DHS 1986, DHS 1996, PNDS 2006, PNS 2013. Coloured dots show the average coverage in each wealth quintile. Q1 is the $20 \%$ poorest wealth quintile; Q5 is the $20 \%$ richest. The distance between quintiles 1 and 5 represents absolute inequality

the Farmácia Popular, a program that delivers free or heavily subsided medicines for diabetes, hypertension, asthma, and other common diseases through accredited private pharmacies $[5,26]$.

The Brazilian healthcare system is a mix of public and private services, and users are free to choose between them. Public health services are provided mostly by public facilities at the primary care level, and by private and philanthropic hospitals at tertiary level. The system is financed through direct taxes and social contributions $[5,26]$. Public funding for the SUS has been steadily increasing over the years in both absolute values and in proportion of GDP. The percentage of the GDP spent on health increased from $7.2 \%$ in 2000 to $9.5 \%$ in 2012, in addition, the government funding accounted for $47.5 \%$ of the expenditure on health in 2012.

The public health expenditure share of the GDP in all levels of government - federal, state and municipal - increased from 2.9 to $3.9 \%$ between 2000 and 2011 [27]. Despite these advances, the public health expenditure in Brazil is still much lower compared to other countries with universal health systems [28]. Total health expenditures per capita have also increased steadily over the years; however, the government still accounted for less 


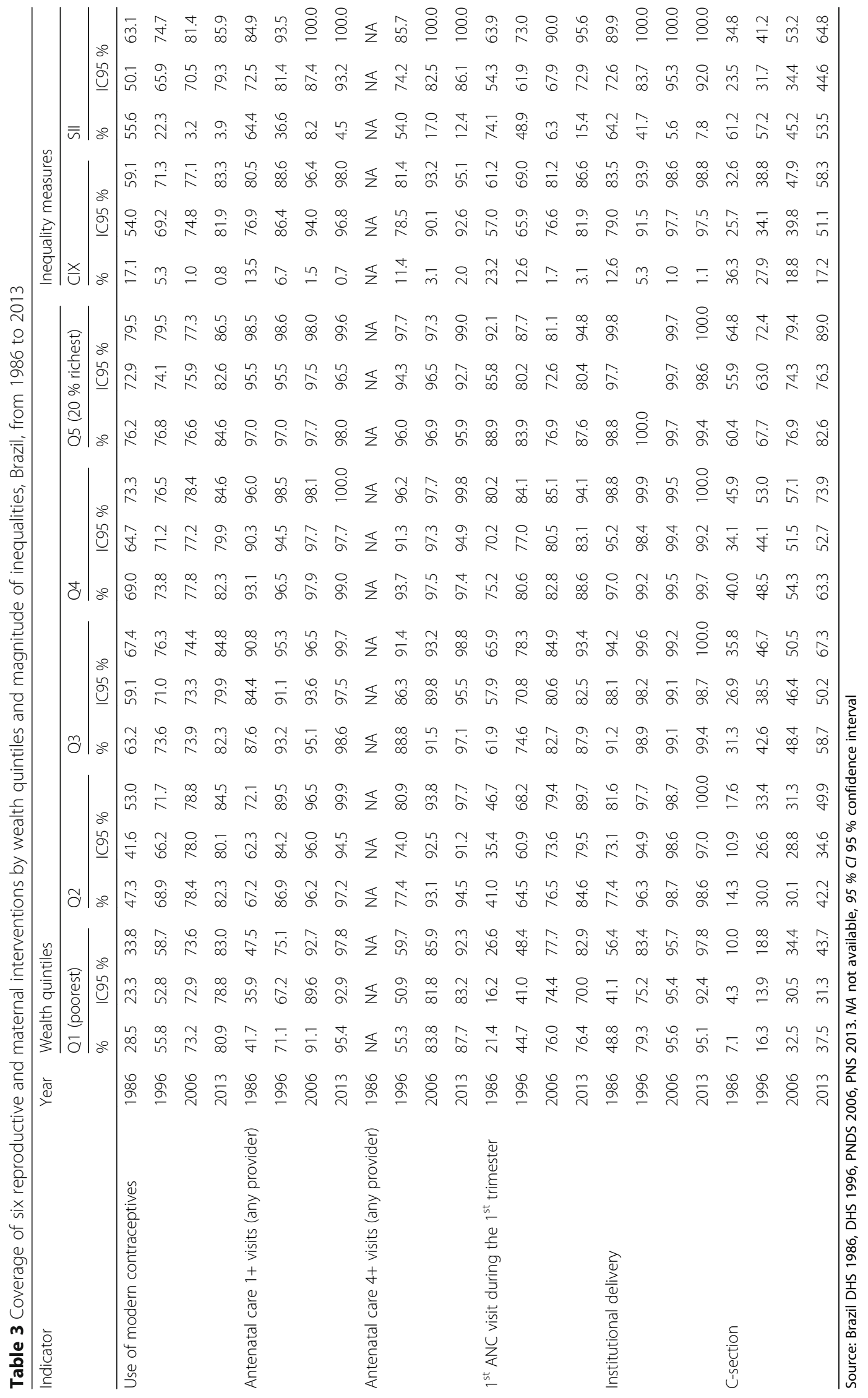




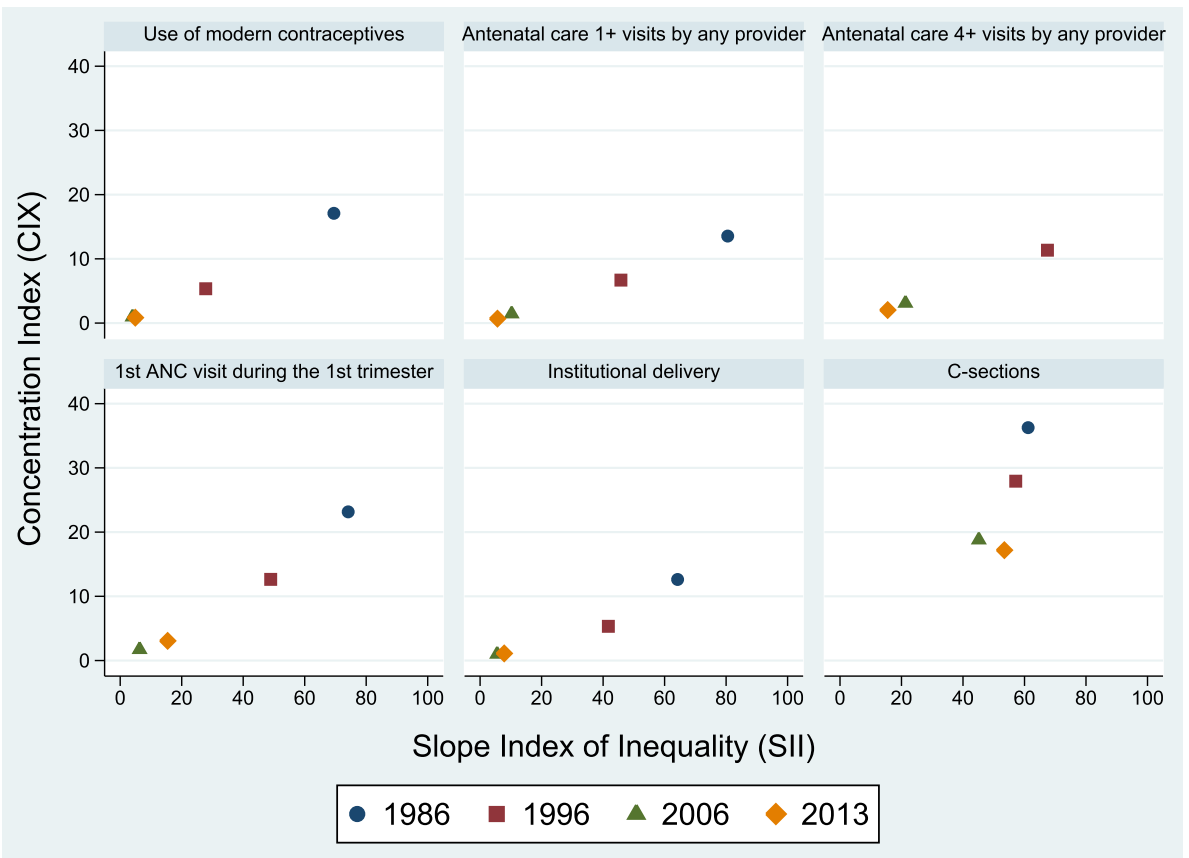

Fig. 5 Scatter diagrams of concentration index and slope index of inequality for six reproductive and maternal interventions, Brazil, from 1986 to 2013. Source: Brazil DHS 1986, DHS 1996, PNDS 2006, PNS 2013

than $50 \%$ of total health expenditure by 2012 [29]. The remainder results from a combination of out-of-pocket and private insurance spending, which is among the highest levels of private spending on health in Latin America [30].

Additional evidence shows that out-of-pocket spending as a proportion of total spending varies little between the poorest and wealthiest classes [5, 31]. For instance, the catastrophic health expenditure $(10 \%$ or more of capacity to pay based on household consumption) was $18.4 \%$ from the poorest and $17.7 \%$ for the wealthiest in 2008-2009 [32]. However, rich and poor spend these funds in different ways. Among the latter, out-of-pocket expenditures are mostly due to purchasing medicines, whereas the richest spend most on private health insurance $[5,31]$.

Our results on $\mathrm{C}$-section rates confirm the disturbing trends documented by the nationwide information system (DATASUS) [33]. Among the wealthiest quintile the proportion of C-sections was above $80 \%$ in 2013. These rates are unacceptable high considering those recommended by WHO despite several efforts to encourage vaginal deliveries and limit $\mathrm{C}$-sections: payment of delivery analgesia for SUS patients (1998), the Pact for C-section Rate Reduction between the Brazilian Ministry of Health and state health departments (2000), enforcement of a ceiling of $27 \%$ Csection rate for states that did not sign the Pact (2002), and a national mass campaign, "Humanization of Normal Childbirth and Reduction of Unnecessary Cesareans" (2006) [34]. In Brazil, obstetricians assist almost all deliveries regardless of financing or budget constraints, and their convenience may play an important role in the decision about the type of delivery. There is widespread evidence that doctors' attitudes during the prenatal and peri-delivery period may increase the likelihood of a C-section [34]. Unless strong and immediate action is taken, Brazil is at risk of reaching universal coverage for an intervention which is estimated to be necessary at most for $15 \%$ of all deliveries [35].

A main limitation of our analyses is that some of the surveys failed to employ internationally-standardized questionnaires, so it was not possible to estimate key $\mathrm{RMNCH}$ indicators, nor to assess time trends for more than a few indicators. Standardized surveys, carried out every $3-5$ years, are essential for monitoring progress and identifying trends in inequalities. It is worth noting that other relevant dimensions of social inequalities in intervention coverage were not assessed, including those associated with women's schooling or ethnic group.

\section{Conclusions}

In summary, there was enormous progress from 1986 to 2013 for key interventions in reproductive and maternal health, both in terms of coverage and inequality. Disparities in $\mathrm{C}$-section rates remain, but these are due to exceedingly high rates of unnecessary procedures among the rich, rather than low rates among the poor. 
Table 4 Annual changes in coverage and inequality measures in six reproductive and maternal interventions, Brazil, from 1986 to 2013

\begin{tabular}{|c|c|c|c|c|c|}
\hline \multirow[t]{2}{*}{ Indicator } & \multirow[t]{2}{*}{ Group } & & \multicolumn{3}{|c|}{ Average annual change } \\
\hline & & & Coefficient & SE & $p$-value \\
\hline \multirow[t]{5}{*}{ Use of modern contraceptives } & Overall & & 0.82 & 0.04 & $<0.001$ \\
\hline & Coverage & Q1 (poorest) & 1.74 & 0.08 & $<0.001$ \\
\hline & & Q5 (wealthiest) & 0.25 & 0.06 & $<0.001$ \\
\hline & Inequality measures & $\mathrm{CIX}$ & -0.37 & 0.03 & $<0.001$ \\
\hline & & SII & -1.63 & 0.12 & $<0.001$ \\
\hline \multirow[t]{5}{*}{ Antenatal care $1+$ visits (any provider) } & Overall & & 0.61 & 0.04 & $<0.001$ \\
\hline & Coverage & Q1 (poorest) & 1.77 & 0.10 & $<0.001$ \\
\hline & & Q5 (wealthiest) & 0.04 & 0.03 & 0.42 \\
\hline & Inequality measures & $\mathrm{CIX}$ & -0.41 & 0.03 & $<0.001$ \\
\hline & & SII & -2.19 & 0.13 & $<0.001$ \\
\hline \multirow[t]{5}{*}{ Antenatal care $4+$ visits (any provider) } & Overall & & 0.79 & 0.08 & $<0.001$ \\
\hline & Coverage & Q1 (poorest) & 2.06 & 0.19 & $<0.001$ \\
\hline & & Q5 (wealthiest) & 0.06 & 0.08 & 0.48 \\
\hline & Inequality measures & $\mathrm{CIX}$ & -0.55 & 0.06 & $<0.001$ \\
\hline & & SII & -2.59 & 0.28 & $<0.001$ \\
\hline \multirow[t]{5}{*}{ 1st ANC visit during the 1st trimester } & Overall & & 1.02 & 0.06 & $<0.001$ \\
\hline & Coverage & Q1 (poorest) & 2.63 & 0.11 & $<0.001$ \\
\hline & & Q5 (wealthiest) & -0.36 & 0.11 & $<0.001$ \\
\hline & Inequality measures & $\mathrm{CIX}$ & -0.81 & 0.05 & $<0.001$ \\
\hline & & SII & -2.57 & 0.19 & $<0.001$ \\
\hline \multirow[t]{5}{*}{ Institutional delivery } & Overall & & 0.34 & 0.04 & $<0.001$ \\
\hline & Coverage & Q1 (poorest) & 1.29 & 0.11 & $<0.001$ \\
\hline & & Q5 (wealthiest) & 0.03 & 0.02 & 0.18 \\
\hline & Inequality measures & $\mathrm{CIX}$ & -0.31 & 0.03 & $<0.001$ \\
\hline & & SII & -2.38 & 0.18 & $<0.001$ \\
\hline \multirow[t]{5}{*}{ C-sections } & Overall & & 0.78 & 0.06 & $<0.001$ \\
\hline & Coverage & Q1 (poorest) & 1.28 & 0.08 & $<0.001$ \\
\hline & & Q5 (wealthiest) & 0.84 & 0.11 & $<0.001$ \\
\hline & Inequality measures & CIX & -0.73 & 0.09 & $<0.001$ \\
\hline & & SII & -0.46 & 0.19 & 0.06 \\
\hline
\end{tabular}

Source: Brazil DHS 1986, DHS 1996, PNDS 2006, PNS 2013

$S E$ standard error, SIl slope index of inequality, CIX concentration index

Dissemination of the lessons learned is Brazil is particularly relevant in light of the focus on universal health coverage and equity which are key aspects of the Sustainable Development Goals (SDGs) of the 2030 Agenda for Sustainable Development adopted by world leaders in September 2015.

Despite such progress, the mortality rates of children and mothers remain several fold higher in Brazil than in the best-performing countries $[36,37]$ indicating that there is still much room for improvement. Substantial challenges remain for the Brazilian health system, including reforming its financial structure to ensure universality and long term sustainability, renegotiating public and private roles, and assuring quality and efficiency of care while minimizing medicalization and ensuring patient safety - as exemplified by the high Csection rates [5]. In terms of equity, the overarching challenge is how to reach those who are hardest to reach, such as rural populations in the Amazon rainforest and northeast regions, indigenous groups, and families living in Brazilian municipalities where with insufficient human resources for health [6]. Also, ensuring universal access is insufficient unless high-quality care is provided and missed opportunities for promoting 
other interventions is assured [5, 38, 39]. We hope that our findings will inform policy debates on strategies to achieve universal coverage and to reduce health inequalities in other low- and middle-income countries, and showcase the importance of tracking progress by regularly collecting data.

\section{Funding}

This article was made possible with funds from the Wellcome Trust [Grant Number: 101815/Z/13/Z]; Bill \& Melinda Gates Foundation; Associação Brasileira de Saúde Coletiva (ABRASCO); Ministry of Health of Brazil. The funders had no role in the writing of this article.

\section{Availability of data and materials}

Data supporting our findings can be found in the following links:

- DHS surveys (1986 and 1996): http://dhsprogram.com/

- Pesquisa Nacional de Demografia e Saúde - 2006: http:// bvsms.saude.gov.br/bvs/pnds/index.php

- Pesquisa Nacional de Saúde - 2013: http://www.ibge.gov.br/home/ estatistica/populacao/pns/2013/

\section{Authors' contributions}

All authors participated in the preparation of the manuscript and approved its final version for submission. AJDB and CGV conceived the research question. GVAF and MCRM contributed equally by conducting the analyses and writing the manuscript. FM conducted the review of the literature and assisted with the editing of the paper. CGV and AJDB supervised the analysis and interpretation of the findings as well as the writing of the paper.

\section{Competing interests}

The authors declare that they have no competing interests.

\section{Consent for publication}

Not applicable.

\section{Ethics approval and consent to participate}

We only used publicly available data from national surveys in our analyses, so that ethical clearance was the sole responsibility of the institutions that carried out the surveys. Further information about the surveys and ethics can be found in their respective websites. The PNS project was approved by the National Commission of Ethics in Research (CONEP) in June 2013, Regulation No. 328.159 .

Received: 30 April 2016 Accepted: 12 September 2016

Published online: 17 November 2016

\section{References}

1. Pan American Health Organization. Health in the Americas: 2012 Edition. Regional outlook and country profiles. Washington: PAHO; 2012.

2. Restrepo-Mendez MC, Barros AJ, Requejo J, Duran P, Serpa LA, Franca GV, Wehrmeister FC, Victora CG. Progress in reducing inequalities in reproductive, maternal, newborn', and child health in Latin America and the Caribbean: an unfinished agenda. Rev Panam Salud Publica. 2015;38:9-16.

3. de Andrade LO, Pellegrini Filho A, Solar O, Rigoli F, de Salazar LM, Serrate PC, Ribeiro KG, Koller TS, Cruz FN, Atun R. Social determinants of health, universal health coverage, and sustainable development: case studies from Latin American countries. Lancet. 2015;385:1343-51.

4. Atun R, de Andrade LO, Almeida G, Cotlear D, Dmytraczenko T, Frenz P, Garcia P, Gomez-Dantes O, Knaul FM, Muntaner C, et al. Health-system reform and universal health coverage in Latin America. Lancet 2015:385:1230-47

5. Paim J, Travassos C, Almeida C, Bahia L, Macinko J. The Brazilian health system: history, advances, and challenges. Lancet. 2011;377:1778-97.

6. Victora CG, Aquino E, do Carmo Leal M, Monteiro CA, Barros FC, Szwarcwald CL. Maternal and child health in Brazil: progress and challenges. Lancet. 2011;377:1863-76

7. Fleury S. Brazilian sanitary reform: dilemmas between the instituing and the institutionalized. Cien Saude Colet. 2009;14:743-52.
8. Fleury S. Brazil's health-care reform: social movements and civil society. Lancet. 2011:377:1724-5.

9. Paim JS. The Citizen Constitution and the 25th anniversary of the Brazilian Unified National Health System (SUS). Cad Saude Publica. 2013;29:1927-36.

10. Barros AJD, Victora CG, Cesar JA, Neumann NA, Bertoldi AD. Brazil: Are Health and Nutrition Programs Reaching the Neediest? In: Gwatkin DR, Wagstaff A, Yazbeck AS, editors. Reaching the poor with Health, Nutrition, and Population Services - What Works, What Doesn't, and Why. Washington: The World Bank; 2005.

11. Sánchez-Ancochea D, Mattei L. Bolsa Família, poverty and inequality: Political and economic effects in the short and long run. Global Soc Policy. 2011;11:299

12. Rasella D, Aquino R, Santos CA, Paes-Sousa R, Barreto ML. Effect of a conditional cash transfer programme on childhood mortality: a nationwide analysis of Brazilian municipalities. Lancet. 2013:382:57-64.

13. Brasil. Sociedade Civil Bem-Estar Familiar no Brasil (BEMFAM)/Instituto para Desenvolvimento de Recursos (IRD). Pesquisa Nacional sobre Saúde Materno-Infantil e Planejamento Familiar - PNSMIPF - Brasil, 1986. Rio de Janeiro: BENFAM; 1987.

14. Brasil. Sociedade Civil Bem-Estar Familiar no Brasil (BEMFAM). Pesquisa Nacional Sobre Demografia e Saúde - 1996. Rio de Janeiro: BEMFAM; 1997.

15. Brasil. Ministério da Saúde. PNDS 2006 - Pesquisa Nacional de Demografia e Saúde da Criança e da Mulher. Braślila/DF: Ministério da Saúde; 2008.

16. Instituto Brasileiro de Geografia e Estatística - IBGE. Pesquisa Nacional de Saúde - 2013. Rio de Janeiro: IBGE; 2014

17. Rutstein SO, Johnson K. The DHS wealth index. DHS comparative reports. Calverton: ORC Macro; 2004

18. Harper S, Lynch J. Methods for measuring cancer disparities: Using data relevant to healthy people 2010: cancer related objectives. Bethesda: National Cancer Institute; 2005.

19. Barros AJ, Victora CG. Measuring coverage in $\mathrm{MNCH}$ : determining and interpreting inequalities in coverage of maternal, newborn, and child health interventions. PLoS Med. 2013;10:e1001390.

20. Brazil: Standard DHS, 1986 [http://dhsprogram.com/what-we-do/survey/ survey-display-2.cfm]

21. Brazil: Standard DHS, 1996 [http://dhsprogram.com/what-we-do/survey/ survey-display-85.cfm]

22. PNDS - Pesquisa Nacional de Demografia e Saúde (2006) [http://bvsms. saude.gov.br/bvs/pnds/index.php]

23. Pesquisa Nacional de Saúde 2013 [http://www.ibge.gov.br/home/estatistica/ populacao/pns/2013/]

24. United Nations Development Programme (UNDP). The 2015 Human Development Report: Work for Human Development. New York: UNDP; 2015.

25. International Labour Organization (ILO). Global Wage Report 2014/15 Wages and income inequality. Geneva: ILO; 2015.

26. Marten R, Mclntyre D, Travassos C, Shishkin S, Longde W, Reddy S, Vega J. An assessment of progress towards universal health coverage in Brazil, Russia, India, China, and South Africa (BRICS). Lancet. 2014:384:2164-71.

27. Piola SF, Paiva ABD, Sá EBD, Servo LMS. Financiamento público da saúde: uma história à procura de rumo. Rio de Janeiro: Instituto de Pesquisa Econômica Aplicada; 2013.

28. World Health Organization. World health statistics 2014. Geneva: WHO; 2014

29. The World Bank. Health expenditure, total (\% of GDP) [http://data. worldbank.org/indicator/SH.XPD.TOTL.ZS]

30. Sunil AR, Cavagnero E, Class D, Ferl K. Brazil - Health financing profile. Washington: World Bank Group; 2014.

31. Barros AJ, Bastos JL, Damaso AH. Catastrophic spending on health care in Brazil: private health insurance does not seem to be the solution. Cad Saude Publica. 2011;27 Suppl 2:S254-62.

32. Boing AC, Bertoldi AD, Barros AJ, Posenato LG, Peres KG. Socioeconomic inequality in catastrophic health expenditure in Brazil. Rev Saude Publica. 2014:48:632-41.

33. Barros FC, Matijasevich A, Maranhao AG, Escalante JJ, Rabello Neto DL, Fernandes RM, Vilella ME, Matos AC, Albuquerque C, Leon RG, Victora CG Cesarean sections in Brazil: will they ever stop increasing? Rev Panam Salud Publica. 2015:38:217-25.

34. Barros AJ, Santos IS, Matijasevich A, Domingues MR, Silveira M, Barros FC, Victora CG. Patterns of deliveries in a Brazilian birth cohort: almost universal cesarean sections for the better-off. Rev Saude Publica. 2011;45:635-43. 
35. World Health Organization. WHO statement on caesarean section rates. Geneva: WHO; 2015

36. United Nations Children's Fund (UNICEF). The state of the world's children 2014 in numbers. Revealing disparities, advancing children's rights. New York: UNICEF; 2014.

37. WHO. UNICEF. UNFPA. World Bank Group. The United Nations Population Division. Trends in maternal mortality: 1990 to 2015: estimates by WHO, UNICEF, UNFPA, World Bank Group and the United Nations Population Division. Geneva: WHO; 2015.

38. UNICEF and World Health Organization. Countdown to 2015: A Decade of Tracking Progress for Maternal, Newborn and Child Survival - The 2015 Report. Geneva: WHO; 2015.

39. World Health Organization. Quality of care : a process for making strategic choices in health systems. Geneva: WHO; 2006.

Submit your next manuscript to BioMed Central and we will help you at every step:

- We accept pre-submission inquiries

- Our selector tool helps you to find the most relevant journal

- We provide round the clock customer support

- Convenient online submission

- Thorough peer review

- Inclusion in PubMed and all major indexing services

- Maximum visibility for your research

Submit your manuscript at www.biomedcentral.com/submit
Biomed Central 